\title{
NIEMANN PICK DISEASE - A CASE REPORT
}

\author{
Vaibhav Mane, R. T. Joshi
}

1. Assistant Professor, Department of Pathology, Bharati Vidyapeeth Medical College and Hospital. Sangli,
Maharashtra.
2. Professor, Department of Pathology, Bharati Vidyapeeth Medical College and Hospital. Sangli. Maharashtra.

\section{CORRESPONDING AUTHOR}

Dr. Vaibhav P. Mane

Vaishnavi Pathology Laboratory, Shop No.2, Kore House, Vishrambag, Sangli

416415, Maharashtra.

E-mail: vaishnavilab@rediffmail.com

Ph: 00919422041490.

ABSTRACT: Niemann Pick Disease (NPD) is a rare autosomal recessive metabolic disease characterized by lysosomal lipid storage. The disease is caused by deficiency of enzyme, acid sphingomyelinase (ASM) which leads to accumulation of sphingomyelin \& other lipids in reticuloendothelial cells of various organs like liver, spleen, bone marrow, lymph node, brain, nerves and kidney. Four types of the disease have been identified which are A, B, C and D. The type $\mathrm{C}$ is divided into types $\mathrm{C} 1$ and $\mathrm{C} 2$, each caused by a different gene mutation.

We report a case of Niemann Pick Disease type B. The patient was a 10 month male child who presented with repeated episodes of vomiting and loose motions. His blood counts revealed pancytopenia. Bone marrow (BM) aspiration was performed which showed many large histiocytes with foamy cytoplasm- Niemann Pick cells which are characteristic of this disease. Further confirmatory investigations were not done because of nonaffordability of parents. At present no definite treatment is available however newer treatment modalities like Bone Marrow transplant, enzyme replacement therapy and gene therapy are likely to be useful especially in NPD type B. However such treatment is unlikely to prevent or reverse the major neurological complications of NPD type A. Supportive treatment through nutrition,medication, physical therapy can help to improve quality of life.

KEYWORDS: Niemann Pick Disease, NPD Type B, bone marrow, liver biopsy, ASM -acid sphingomyelinase.

INTRODUCTION: NPD is due to deficient activity of sphingomyelinase, a lysosomal enzyme encoded by the SMPD1 gene located on chromosome bands 11p15.1-p15.4(1).It results in sphingomyelin accumulation in the reticuloendothelial system (1).It also gets deposited in CNS, lung, liver, spleen etc.

The incidence of type A \& B in general population is estimated to be 1 in 250,000 while that of type $C$ is 1 in 150,000. NPD type A is more common in Ashkenazi Jewish population with estimated incidence of 1 in 40,000 (10) \& the carrier frequency among this population is 1 in 90 (1).Both sex are affected equally.(1)

CASE REPORT: The patient was a 10 month male child who presented with repeated episodes of vomiting and loose motions. His blood counts revealed pancytopenia.

Other biochemical investigations are within normal range. Bone marrow (BM) aspiration was performed which showed many large histiocytes with foamy cytoplasm- 
Niemann Pick cells which are characteristic of this disease. These cells are large histiocytes with central and eccentric nucleus and cytoplasm showing soap bubble appearance. ( Fig 1 )

Further confirmatory investigations were not done because of nonaffordability of parents.

DISCUSSION: The name Niemann Pick is derived from name of German pediatrician Albert Niemann who first reported a case in 1914 and Ludwig Pick (1927) who provided further clinical and pathological description that helped in differentiating this disease from Gaucher's disease ${ }^{(1)}$

Niemann Pick Disease is classified into four subtypes (2)

Niemann Pick Disease type A: classic infantile

Niemann Pick Disease type B: visceral

Niemann Pick Disease type C: subacute / juvenile

Niemann Pick Disease type D: Nova Scotian

NEIMAN PICK DISEASE TYPE A : It usually presents in first few months of life with abdominal swelling, hepatosplenomegaly, feeding difficulties, loss of early motor skills ,recurrent infections and irritability(2) As age advances progressive loss of motor function ,deterioration of intellectual capabilities and in final stage spasticity and rigidity occurs. Blood investigations show pancytopenia.

NEIMAN PICK DISEASE TYPE B: In contrast, NPD type B has variable clinical presentation. Jaundice and hepatosplenomegaly may be detected in early childhood in some patients but may remain barely noticeable in others. In adult life patients may present with pancytopenia \& hepatosplenomegaly. Pulmonary involvement may be detected in the form of diffuse reticular or finely nodular lesions. Patients with lung lesions may present with dyspnoea, decreased oxygen saturation and repeated life threatening bronchopneumonia or cor pulmonale. Rarely involvement of retinal neurons (cherry red spots), CNS and skeletal system are noted. These patients are not affected intellectually. The life expectancy of NPD type B patients is highly variable depending on the severity of their symptoms $(3,4)$.

NEIMAN PICK DISEASE TYPE C: NPD type C usually affects children of school age but the disease may strike at any age from infancy to adulthood. Symptoms may include jaundice and large spleen or liver, difficulty in upward and downward eye movement (highly suggestive of NPD type C), clumsiness, problems in walking, slurred and irregular speech, learning difficulties and other neurological abnormalities. Life span is usually short depending upon severity of symptoms (3).

NEIMAN PICK DISEASE TYPE D: It involves a defect that interferes with movement of cholesterol between brain cells. It is now considered as variant of type C.

PROGNOSIS: Infants with Type A die in infancy. Type B children live comparatively longer but require supplemental oxygen due to lung impairment.(4).In Type $C$ and Type D some patients die in childhood while others less affected may live upto adulthood.

PREVENTION: Niemann Pick Disease is autosomal recessive disease. Genetic counseling and genetic testing is recommended for families who may be carriers of Niemann -Pick. 
When both parents are carriers, there is $25 \%$ chance that their child will have the disease and $50 \%$ chance that a child will be carrier.

NPD cases are diagnosed by detection of Niemann Pick cells in aspiration or biopsy of bone marrow, liver and spleen. Diagnosis is confirmed by measuring ASM enzyme activity in peripheral leukocytes, cultured skin fibroblasts, chorionic villi and amniocytes. High performance liquid chromatography (HPLC) using plasma instead of leucocytes is a very reliable and highly sensitive technique to determine ASM activity for accurate diagnosis of NPD patients or carriers(2). Diagnosis of both NPC1 and NPC2 mutations is suggested by demonstration of delayed esterification of LDL- derived cholesterol and increased amount of unesterified cholesterol in fibroblasts. Staining with filipin demonstrates the intracellular accumulation of cholesterol. DNA mapping of patient as well as the carrier parents gives the definite diagnosis $(2,3)$.

CONCLUSION: The clinical manifestations show marked variability in patients among phenotype B, ranging from severe disease in childhood to milder course till old age. Chronic visceral nonneuropathic type B has good prognosis. Life expectancy of patient can be improved by supportive care through nutrition, medication (like lipid lowering drugs), physiotherapy \& specialist care for treatment of complications. Early diagnosis is useful as it allows time to plan for disease management.

At present, as no specific treatment is available, only supportive treatment is offered. Newer modalities like bone marrow transplantation, enzyme replacement therapy and gene therapy are likely to be useful for NPD type B $(5,6)$.

\section{REFERENCES:}

1. John H. Menkes, Franklin G. Moser- Neurological Examination of Child \& Infant In: John H, Menkes Harvey B, Sarnat Beinard, L Maria editors-Child Neurology. 7th ed. Philadelpia: Lippincott Williams \& Wilkins, 2006:91-93.

2. 2. International center for type A \& type B Niemann Pick disease 2010 The Mount Sinai Medical Center www.mssm.edu/research

3. National Institute of Neurological Disorders and Stroke.(NINDS). Niemann Pick Disease Information Page www.ninds.nih.gov/disorders/niemann/niemann.htm

4. Gregory M. Pasteres, Edwin H. Kolodny-Lysosomal Storage Disease. In: Kenneth F. Swaiman, Stephen Ashwal, Donna M. Ferriero editors- Pediatric Neurology: Principle and Practice. Vol I.4th ed. MOSBY Inc, 2006: 673-677.

5. 5 http:/www.pediatriconcall.com /fordoctor/casereport/niemann pick disease. Ira Shah, asp.2006

6. Lynne leradi - Curto: Genetics od Niemann Pick disease. medicine.medscape.com/article/951564-overview\#showall 


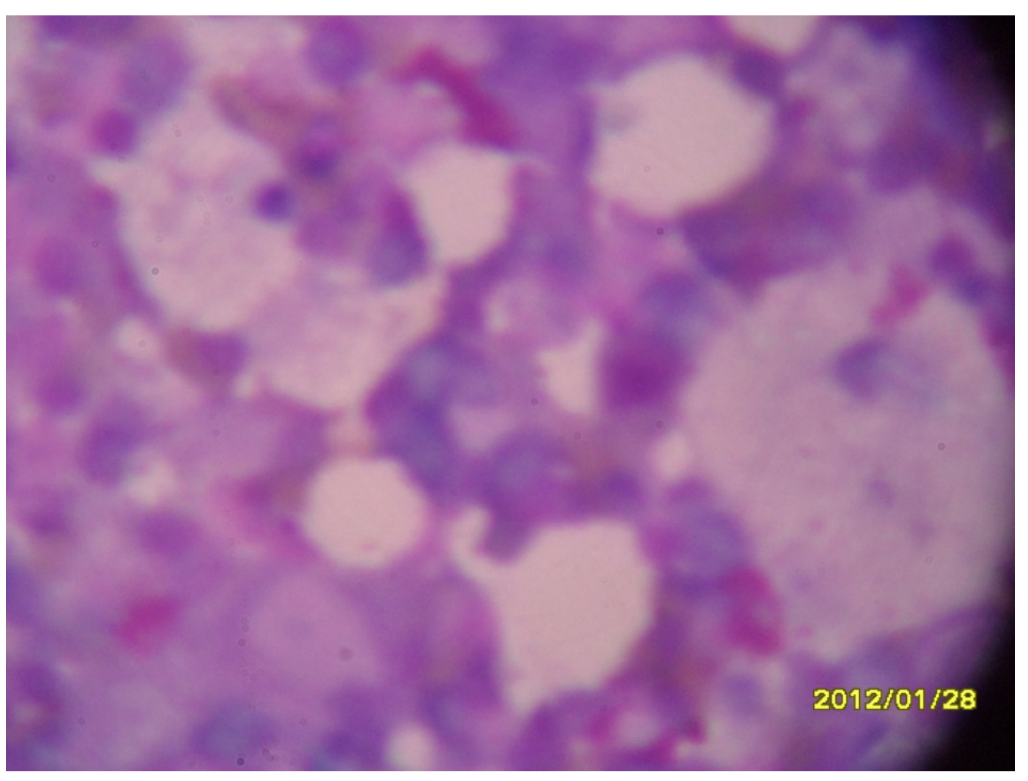

Low power view : Leishmann stain : Neimann Pick Cells .

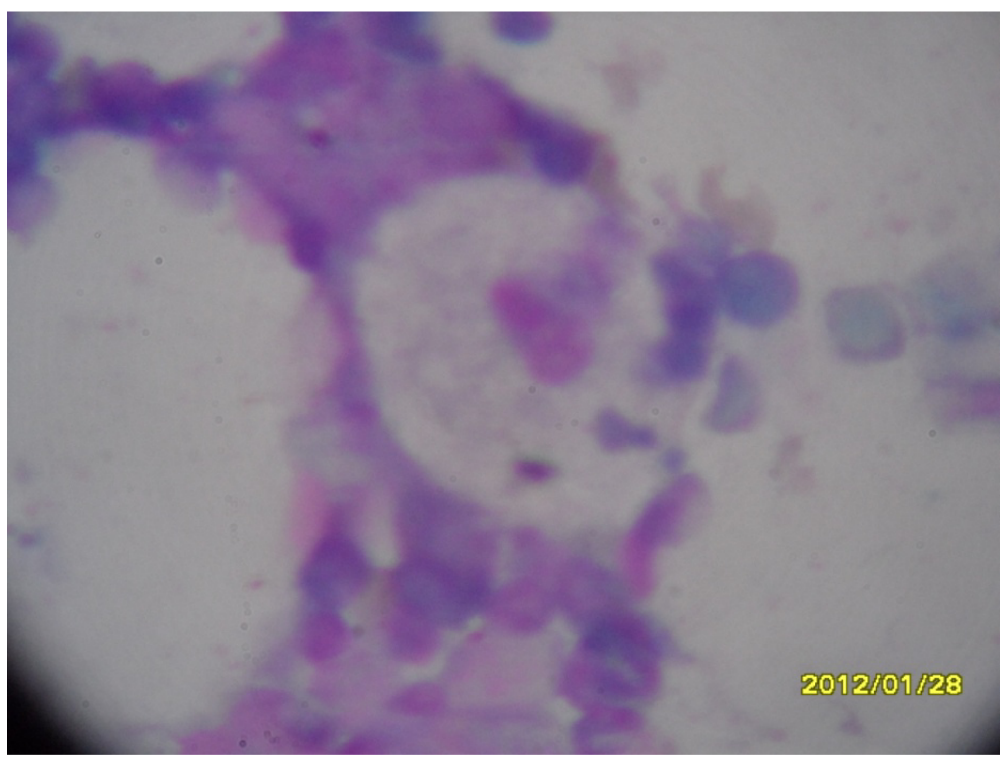

High Power View : Leishmann Stain : Neimann Pick Cell 